\title{
Shear-induced endothelial mechanotransduction: the interplay between reactive oxygen species (ROS) and nitric oxide (NO) and the pathophysiological implications
}

Hsyue-Jen Hsieh ${ }^{1}$, Ching-Ann Liu², Bin Huang ${ }^{3}$, Anne HH Tseng ${ }^{2}$ and Danny Ling Wang ${ }^{2,4^{*}}$

\begin{abstract}
Hemodynamic shear stress, the blood flow-generated frictional force acting on the vascular endothelial cells, is essential for endothelial homeostasis under normal physiological conditions. Mechanosensors on endothelial cells detect shear stress and transduce it into biochemical signals to trigger vascular adaptive responses. Among the various shear-induced signaling molecules, reactive oxygen species (ROS) and nitric oxide (NO) have been implicated in vascular homeostasis and diseases. In this review, we explore the molecular, cellular, and vascular processes arising from shear-induced signaling (mechanotransduction) with emphasis on the roles of ROS and NO, and also discuss the mechanisms that may lead to excessive vascular remodeling and thus drive pathobiologic processes responsible for atherosclerosis. Current evidence suggests that NADPH oxidase is one of main cellular sources of ROS generation in endothelial cells under flow condition. Flow patterns and magnitude of shear determine the amount of ROS produced by endothelial cells, usually an irregular flow pattern (disturbed or oscillatory) producing higher levels of ROS than a regular flow pattern (steady or pulsatile). ROS production is closely linked to NO generation and elevated levels of ROS lead to low NO bioavailability, as is often observed in endothelial cells exposed to irregular flow. The low NO bioavailability is partly caused by the reaction of ROS with NO to form peroxynitrite, a key molecule which may initiate many pro-atherogenic events. This differential production of ROS and RNS (reactive nitrogen species) under various flow patterns and conditions modulates endothelial gene expression and thus results in differential vascular responses. Moreover, ROS/RNS are able to promote specific post-translational modifications in regulatory proteins (including S-glutathionylation, S-nitrosylation and tyrosine nitration), which constitute chemical signals that are relevant in cardiovascular pathophysiology. Overall, the dynamic interplay between local hemodynamic milieu and the resulting oxidative and S-nitrosative modification of regulatory proteins is important for ensuing vascular homeostasis. Based on available evidence, it is proposed that a regular flow pattern produces lower levels of ROS and higher NO bioavailability, creating an anti-atherogenic environment. On the other hand, an irregular flow pattern results in higher levels of ROS and yet lower NO bioavailability, thus triggering pro-atherogenic effects.
\end{abstract}

Keywords: Endothelial cell, Mechanotransduction, Reactive oxygen species (ROS), Nitric oxide (NO), Shear stress, Flow pattern

\footnotetext{
* Correspondence: lingwang@ibms.sinica.edu.tw

${ }^{2}$ Institute of Biomedical Sciences, Academia Sinica, Taipei 11529, Taiwan

${ }^{4}$ Institute of Medical Sciences, College of Medicine, Tzu-Chi University,

Hualien 97004, Taiwan

Full list of author information is available at the end of the article
} 


\section{Review} Introduction

Blood vessels are constantly under the influence of hemodynamic forces including: 1) shear stress, which is the tangential frictional force acting on the vessel wall due to blood flow, defined as force/wall area (e.g., dyn $/ \mathrm{cm}^{2}$ ); 2) hydrostatic pressure, the perpendicular force acting on the vascular wall; and 3) cyclic strain, the circumferential stretch of the vessel wall (Figure 1A) [1]. As an interface between the blood flow and vessel wall, endothelial cells (ECs) is exposed to these hemodynamic forces. Indeed, it is well established that the signaling arising from EC-blood flow interaction are important determinants of vascular homeostasis. ECs and neighboring smooth muscle cells $(\mathrm{SMC})$ are also involved in signaling communication, the net result of which influences vascular remodeling, myogenic tone and vascular response to vasoactive agonists.
Extensive studies over the past few decades have showed that vascular ECs sense mechanical force and transduce them into biological responses [2-5], termed as mechanotransduction. This complex process involves perturbation of sensors that generate biochemical signals that initiate complex and multiple signaling cascades that eventually drive short- and long- term vascular responses. Candidate sensors are ion channels, receptor tyrosine kinases, G protein-coupled receptors, junction proteins, integrins, cytoskeletal network, membrane lipids and the glycocalyx (Figure 1B) [5].

The geometric structure of the vascular tree comprises straight, curved, branched, converged, diverged, and other complex features, thus rendering the hemodynamic environment in the vascular tree extremely complicated. In the straight part of an artery, the hemodynamic flow pattern is typically laminar

A

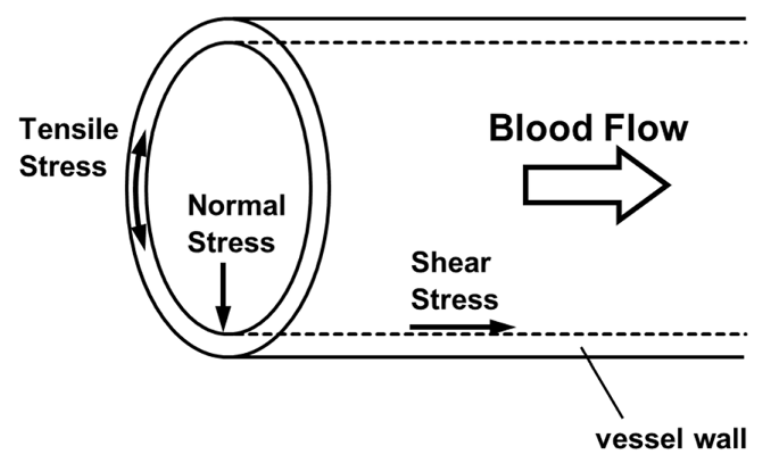

B

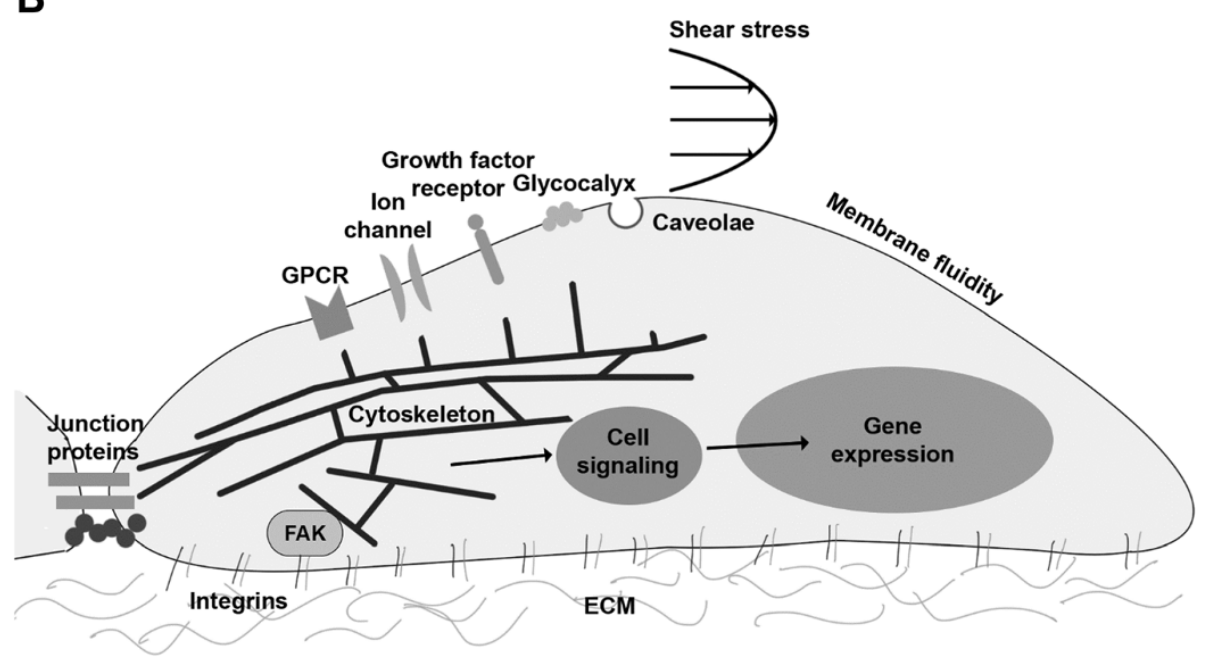

Figure 1 Hemodynamic forces acting on the blood vessel wall and the potential sensors initiating mechanotransduction.

(A) Hemodynamic forces experienced by the blood vessel wall including: 1) shear stress, which is the tangential frictional force acting on the vessel wall due to blood flow, defined as force/wall area (e.g., dyn $\left./ \mathrm{cm}^{2}\right)$; 2) normal stress, which is the force acting perpendicularly on the vessel wall due to hydrostatic pressure; and 3) tensile stress, which is the force acting on the vessel wall in the circumferential direction due to stretch of the vessel wall. (B) Potential mechano-sensors likely to initiate mechanotransduction in endothelial cells, including G protein-coupled receptor (GPCR), mechano-activated ion channels, growth factor receptor, glycocalyx, caveolae, membrane lipids (fluidity), junction proteins, cytoskeleton network, integrins, focal adhesion kinase (FAK), etc. [5]. In mechanotransduction process the mechanical signals trigger the perturbation of these mechano-sensors, thus generating biochemical signals and initiating mechano-sensitive signaling cascades that lead to downstream gene expression. 
with an average shear stress of $10-70 \mathrm{dyn} / \mathrm{cm}^{2}$ on the vascular ECs, and thus the flow condition is termed regular flow. However, in the curved, branched, and diverged regions of arterial tree, the hemodynamic flow becomes disturbed, leading to the formation of eddies, and the occurrence of low and reciprocating (oscillatory) shear stress regions, and thus the flow condition is termed irregular flow [1]. In vivo observations have revealed that atherosclerotic lesions preferentially localize at bends and bifurcations in the arterial tree where irregular flow is likely to occur; it is now well accepted that regular flow maintains vascular homeostasis while irregular flow lead to unfavorable vascular responses that eventually result in vascular diseases [6]. Later studies have shown that regular flow (either steady or pulsatile) causes activation and regulation of anti-inflammation and anti-atherogenic genes, whereas irregular flow with a low, reciprocating (oscillatory) shear stress, or disturbed flow pattern increases transcription of pro-atherogenic genes [1].

Studies of the past decade indicate that reactive oxygen species (ROS) generated in response to altered flow or cyclic strain settings play a key role in the signaling mechanisms and affect vascular homeostasis [7-9]. ROS (a collective term that refers to oxygen radicals such as superoxide, $\mathrm{O}_{2}$ - and hydroxyl radical, $\mathrm{OH}$. and to nonradical derivatives of $\mathrm{O}_{2}$, including $\mathrm{H}_{2} \mathrm{O}_{2}$ and ozone $\left(\mathrm{O}_{3}\right)$ in cells and tissue is determined not merely by cellular production but also by the antioxidant defenses; indeed antioxidant enzymes such as superoxide dismutase, catalase, glutathione peroxidase, thioredoxin, peroxiredoxins and heme oxygenase- 1 regulate and often reduce the level of ROS in biological systems.

Apart from ROS, reactive nitrogen species [RNS such as nitric oxide (NO), nitrogen dioxide $\left(\mathrm{NO}_{2}^{-}\right)$, peroxynitrite $\left(\mathrm{OONO}^{-}\right)$, dinitrogen trioxide $\left(\mathrm{N}_{2} \mathrm{O}_{3}\right)$, nitrous acid $\left(\mathrm{HNO}_{2}\right)$, etc.] also play a complex role in endothelial disorders. Nitric oxide (NO) (produced from sources such as endothelial nitric oxide synthase) released from the endothelium due to stimuli such as shear stress, regulates the vascular environment by inhibiting the activity of proinflammatory agents (cytokines, cell adhesion molecules and growth factors released from endothelial cells of the vessel wall and from platelets on the endothelial surface). The interaction of NO with ROS causes the production of several RNS that potentiate cellular damage. This does not generally occur under normal cellular conditions, where the limited ROS and NO produced contribute to vascular homeostasis. However under conditions of excessive ROS production i.e. oxidative stress, elevated levels of ROS cause a decrease in bioavailability of $\mathrm{NO}$ in addition to production of RNS such as peroxynitrite that are implicated in oxidative and nitrosative damage $[10,11]$. NO, besides its direct role in vascular function, also participates in redox signaling by modifying proteins (via S-nitrosation of cysteine residue) and lipids (via nitration of fatty acid) $[12,13]$.

Research of the past decade has documented that overproduction of ROS and/or deregulation of RNS production drives development of heart and cardiovascular diseases $[10,11,14-17]$. The present review emphasizes the interplay between ROS and NO in the context of shear stressinduced mechanosignaling. Our current concepts based on ample published evidence and summarized in Figure 2 are as follows: 1 ) hemodynamic shear stress sensed by various mechanosensors on vascular ECs, trigger signaling pathways that alter gene and protein expression, eventually giving rise to anti-atherogenic or pro-atherogenic responses in the vascular wall depending on the flow patterns. 2) These signaling pathways are ROS/RNS mediated and the eventual physiological responses depend on a large part on the interactions between ROS and $\mathrm{NO}$ and these interactions-modulating redox signalings that drive physiological or pathological processes. The following sections will discuss the shear signaling initiated by various flow patterns, and the effect of ROS/NO interactions on redox signaling in the vasculature.

\section{Sources of ROS and NO production in response to shear}

In general, potential sources of ROS production in ECs include NADPH oxidase (Nox), xanthine oxidase, mitochondria and uncoupled eNOS. In most vascular beds under normal physiological conditions, Nox oxidases appear to be the predominant sources of ROS in ECs under shear stress. Shear stress exerted by blood flow to ECs is sensed via above-mentioned mechano-sensors on EC. These initiate a complex signal-transduction cascade which produces ROS and NO. NO is generated by eNOS activation in which shear stress plays widely regulatory roles at the transcriptional, posttranscriptional and posttranscriptional levels.

\section{NAD(P)H oxidase (Nox)}

NADPH oxidase (Nox) upon activation uses NADPH to reduce oxygen to superoxide anion. Activation of this enzyme requires the assembly of Nox (1-5), regulatory subunits (p22phox, p47phox, p67phox, p40phox) and the small GTPase Rac. Among Nox homologs (Nox 1-5 and Duox 1-2) [17], only Nox 1, 2, 4 and 5 enzymes are known to express in the vascular system. Nox2, also known as pgp91, was first known as an enzymatic complex responsible for respiration burst in phagocyte. Human umbilical vein ECs in culture express all of the components of traditional phagocytic NADPH oxidase (including Nox2). Nox1, similar to Nox2, forms a membrane-bound cytochrome with p22phox. However, p47phox and p67phox can be replaced by Noxo1 and Noxa1. Compared with Nox2, Nox1 possesses moderate physiological activity due to its low expression and specific regulatory units and 


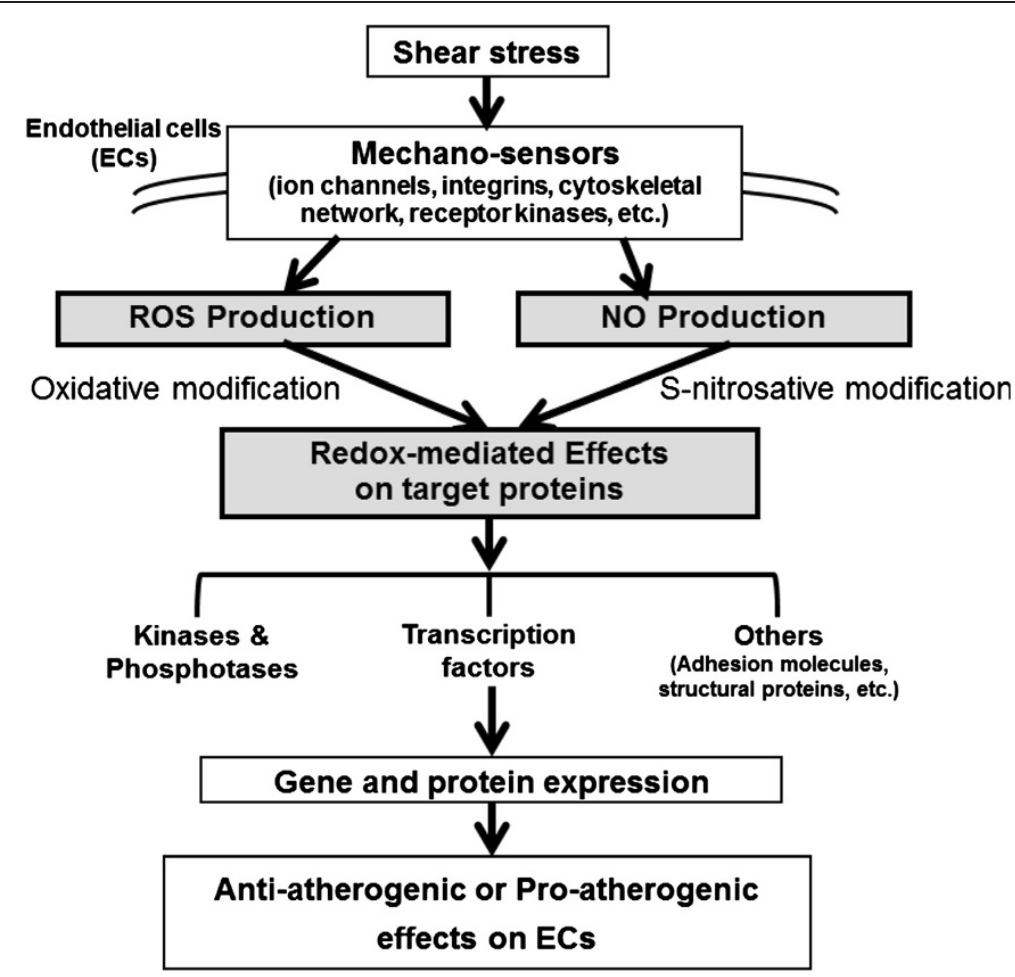

Figure 2 Roles of ROS/NO in mechano-sensor mediated redox signaling in ECs exposed to shear stress. Hemodynamic shear stress is detected by various mechano-sensors present on the membrane of ECs, triggering a network of signaling pathways that alter gene and protein expression, eventually leading to anti-atherogenic or pro-atherogenic effects on ECs. In this process, ROS triggers oxidative modification and NO triggers S-nitrosation of many target molecules, together with activation of antioxidant and pro-oxidant enzymes to regulate the redox status of ECs. Shear stress with a regular flow pattern (steady or pulsatile) produces lower levels of ROS (hence to be anti-atherogenic) than shear stress with an irregular flow pattern (disturbed or oscillatory) that is pro-atherogenic.

signaling cascades. Nox4 is frequently coexpressed with Nox1 and Nox2. Similar to Nox1 and Nox2, Nox4 binds to p22phox. However, Rac1 does not activate Nox4. Nox4 mRNA level in ECs is significantly higher than Nox1 and Nox2 and is indicated to be a primary source of intracellular ROS in ECs. Nox5 expression is limited to fewer tissues including VSMCs and ECs. The striking structural difference of Nox 5 from other Nox enzymes is the presence of an additional cytosolic $\mathrm{N}$-terminal segment, containing 4 calcium binding EF-hands. An increase of intracellular calcium concentration in ECs triggers high superoxide production by Nox5. Under physiological conditions Nox proteins and their products superoxide and hydrogen peroxide act as structural and signaling molecules to regulate cell growth and differentiation, wound repair and control of vascular tone. In this review, we emphasize on the role of Nox enzymes in shear stress-induced ROS production.

To study the shear flow effects on ECs, various apparatus have been designed to examine the influence of various flow patterns (and thus shear stress) on ECs in vitro (Figures 3 and 4 illustrate the detailed design and provide the description of these apparatuses and types of flow). Using these chambers, it was observed that steady laminar flow ( $5 \mathrm{dyn} / \mathrm{cm}^{2}$ ) led to only a transient induction of Nox activity [18,19]; in contrast, atherogenic oscillatory shear stress (OSS, $\pm 3 \sim 5 \mathrm{dyn} / \mathrm{cm}^{2}$ ) or negative shear stress (flow reversal) caused sustained Nox activity and $\mathrm{O}_{2}{ }^{-}$production $[20,21]$, indicating a role for directional activation of Nox. However, prolonged shear stress $\left(30 \mathrm{dyn} / \mathrm{cm}^{2}\right.$, for 24 h) was observed to down-regulate Nox subunits p47phox and Nox2 (gp91phox); $\mathrm{O}_{2}$ production was also reduced [22]. Similarly, ECs exposed to long-term arterial laminar shear stress decreased Nox4 expression and reduced $\mathrm{O}_{2}{ }^{\circ}$ production [23]. The Nox4 promoter contains an antioxidant response element (for Nrf2 binding) and an Oct-1 binding site that are responsible for flowdependent down-regulation of Nox4 [23]. However, OSS upregulates Nox 1 and Nox 2 mRNAs while suppressing or inducing Nox4 $[24,25]$. From knockdown experiments it seems that OSS-induced ROS was derived from Nox1 [25]. Pulsatile shear stress (PSS, mean shear stress of $25 \mathrm{dyn} / \mathrm{cm}^{2}$ ) downregulates Nox2 and Nox4 mRNAs [24]. The effect of flow and various flow patterns on Nox 5 or Duox activity has not been investigated yet. But expression and activity of Noxes 1,2 and 4 are differentially regulated by the flow pattern that contributes to ROS production in ECs. 

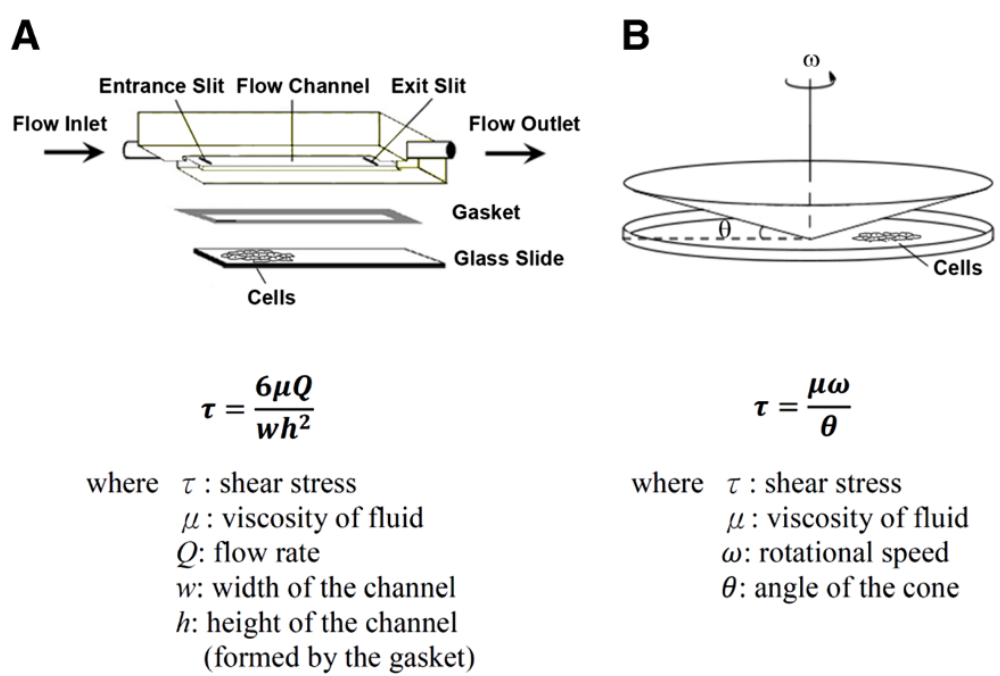

$$
\begin{gathered}
\qquad \boldsymbol{\tau}=\frac{\boldsymbol{\mu} \boldsymbol{\omega}}{\boldsymbol{\theta}} \\
\text { where } \tau: \text { shear stress } \\
\mu: \text { viscosity of fluid } \\
\omega: \text { rotational speed } \\
\theta: \text { angle of the cone }
\end{gathered}
$$

Figure 3 Devices used to carry out in vitro studies to examine the influence of flow (shear stress) on ECs. (A) Parallel-plate flow chamber. In a parallel-plate flow chamber system ECs monolayers are exposed to well-defined flow and thus shear stress (denoted by $\mathrm{T}$ ) in a small channel with fixed height. (B) Cone-and-plate flow chamber. In a cone-and-plate flow chamber system ECs monolayers are exposed to shear stress $(\tau)$ generated by a rotating cone. The magnitude of shear stress can be calculated using the respective formula shown in $\mathbf{A}$ and $\mathbf{B}$.

\section{Mitochondrial respiratory chain, xanthine oxidase and uncoupled eNOS}

Oxidative phosphorylation in the mitochondria causes the proton translocation across the mitochondrial inner membrane to intermembrane space, generating an electrochemical proton gradient that is expressed as mitochondrial membrane potential $\left(\Delta \Psi_{\mathrm{m}}\right)$ and mtROS level increases exponentially as $\Delta \Psi_{\mathrm{m}}$ is hyperpolarized above $-140 \mathrm{mV}$. Previous studies showed that cyclic strain induced ROS production and mitochondria was

A

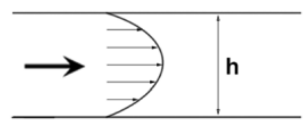

Regular flow: steady or pulsatile (in parallel-plate chamber)

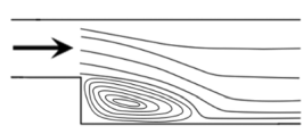

Irregular flow: disturbed or oscillatory (in vertical step-flow chamber)

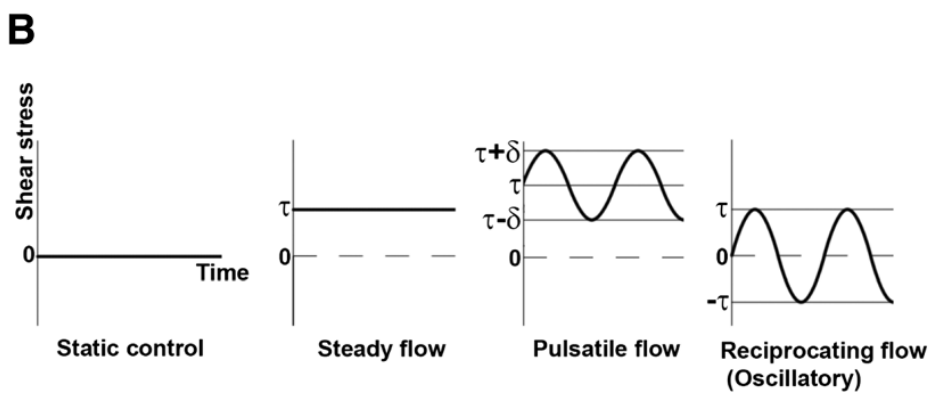

Figure 4 Classification and description of flow patterns. (A) Illustration of regular flow and irregular flow. The flow pattern in a parallel-plate flow chamber is laminar with a parabolic-like velocity profile and the flow condition is termed regular flow, which can be steady or pulsatile. In contrast, the flow pattern in a vertical step-flow chamber is disturbed with the formation of eddies and separation of streamlines and thus the flow condition is termed irregular flow, which can be disturbed or oscillatory. (B) Demonstration of various types of flow. According to the magnitude of shear stress and variation of shear stress with time, they can be categorized as static control, steady flow, pulsatile flow, and reciprocating (oscillatory) flow. For static control, no shear stress is produced because there is no flow. For steady flow, a physiological level of shear stress $(\tau)$ is produced by the flow. For pulsatile flow and reciprocating (oscillatory) flow, cyclic change (e.g. $1 \mathrm{~Hz}$ ) in the level of shear stress is maintained, but the average level of shear stress ( $\tau$ ) of pulsatile flow is relatively higher in comparison with reciprocating (oscillatory) flow, for which the average level of shear stress is zero or very low. 
the source of ROS [26]. With an acute induction of shear stress, mitochondrial complexes I and III generate ROS in coronary arteries [27]. Oscillatory flow was shown to induce mitochondrial superoxide production via NADPH oxidase-JNK signaling pathway [21]. Steady laminar shear-induced NO production mediates a sustained suppression of the activities of respiratory complexes I, II/III, and IV [28]. Mitochondrial ROS generation is regulated by shear stress due to the eNOS-derived NO and RNS inhibit mitochondrial electron transport [28]. Shear stress thus has antioxidant effects in ECs as it partly suppresses mitochondrial respiration via NO. Xanthine oxidase (XO) utilizes NADH, $\mathrm{O}_{2}$ and xanthine/hypoxanthine to generate $\mathrm{O}_{2}$ and $\mathrm{H}_{2} \mathrm{O}_{2}$. Increased $\mathrm{XO}$ activity reportedly impairs flow-dependent and endotheliumdependent vasodilation $[15,16,29]$. Under oscillatory flow, endothelial ROS production in ECs is reported to be derived mainly from XO [30]. Under conditions of limiting L-arginine or cofactor tetrahydrobiopterin (BH4), eNOS is able to exhibit NADPH oxidase activity (eNOS uncoupling), and the resulting $\mathrm{O}_{2}{ }^{-}$may contribute to vascular dysfunction. Endothelial dysfunction in various pathological settings exhibits eNOS uncoupling [31]. Nox1 activation and upregulation mediate eNOS uncoupling in diabetes patients [32] and in endothelium-dependent relaxation impairment [33]. Shear stress-induced NO levels are significantly lower in vessels of aged rats, and this is associated with increased $\mathrm{O}_{2}$ - production from eNOS uncoupling [34].

\section{Influence of shear stress on endothelial nitric oxide oxidase (eNOS)}

Endothelial eNOS is a constitutively expressed enzyme, it is also regulated at the transcriptional, posttranscriptional and posttranslational levels $[35,36]$. Shear stress can activate eNOS by several signaling pathways. Studies on the onset of shear indicates that ECs rapidly respond to shear stress with an acute but transient increase in intracellular calcium that enhances the calmodulin binding to eNOS and increases eNOS activity [37]. In addition, calmodulin activates calmodulin kinase II to phosphorylate eNOS on S1177/1179. However, an increase in diacylglycerol levels can activate PKC to phosphorylate T497 but negatively regulates eNOS activity. Shear stress, similar to VEGF, estrogen and bradykinin, can activate $G$ proteins that stimulate PI3K/Akt [38] and adenylate cyclase $[39,40]$, both of which lead to phosphorylation of serine residues (S617 and S1177/1179 by Akt, S635 and S1177/ 1179 by PKA) on eNOS and hence its activation [36].

Graded increase in shear promotes eNOS expression and activity. Li et al. using artificial capillary modules to study the effects of pulsatile flow/shear stress on ECs reported that ECs adapted to low physiological flow $\left(3 \mathrm{dyn} / \mathrm{cm}^{2}\right)$ followed by high shear $\left(10,15,25 \mathrm{dyn} / \mathrm{cm}^{2}\right)$ environments for up to $24 \mathrm{~h}$ showed graded elevation of eNOS mRNA, protein expression and NO release [41]. In addition to the rapid PI3K-dependent eNOS phosphorylation on S1177, acute shear exposure reduced phosphorylation at T495 due to a decrease in PKC $\delta$ activity $[41,42]$. However, a prolonged $\mathrm{NO}$ production requires an increase of eNOS expression and enzyme activation. Furthermore, ECs with catalase overexpression attenuated the acute shear-induced phosphor-S1177 eNOS and NO production, confirming that acute shear-mediated increase in ROS plays a role in the acute eNOS activation. Under prolonged shear stress, PI3K pathway is not involved in the increased eNOS expression.

Studies with flow chamber module demonstrated that laminar flow triggered AMP-activated protein kinase (AMPK) activation and subsequent phosphorylation of eNOS at S635 and S1179 [43,44]. Recent studies further showed that SIRT1, an $\mathrm{NAD}^{+}$-dependent class III histone deacetylase, played a role by deacetylating eNOS at Lys496 and 506 in calmodulin-binding domain of eNOS and thereby increased eNOS activity [45]. Further studies by Chen et al. demonstrated that shear stress increased SIRT1 level and activity and SIRT1 level was higher in ECs exposed to physiologically relevant pulsatile flow than those under pathologically relevant oscillatory flow. They further showed that AMPK phosphorylation of eNOS was required for the SIRT1 deacetylation of eNOS [46]. Thus, atheroprotective flow increases the level of SIRT1, and SIRT1 acts together with AMPK to promote NO production in endothelium.

Fluid shear stress also induces transcriptional factors, such as Krüppel-like factor (KLF2), which upregulates eNOS expression [47-49]. Steady or PSS markedly activates Nrf2 and induces Nrf2-regulated antioxidant genes, such as heme oxygenase-1 (HO-1) and thioredoxin reductase-1 (TrxR1), and this reduces the level of intracellular $\mathrm{O}_{2}{ }^{-}$, thereby increasing the level of bioavailability NO [50-52]. Thus, ECs under steady or physiological PSS have reduced intracellular ROS and increased bioavailability of NO.

\section{Flow patterns and the production of ROS and NO}

As mentioned above, the geometric structure of the vascular tree drives changes in blood flow which may cause endothelial dysfunction. To carry out in vitro study to examine the influence of flow on ECs, a parallel-plate flow chamber system has been designed for the exposure of ECs monolayers to well-defined flow (and thus shear stress) in a small channel with fixed height (Figure 3A) [53]. Another in vitro system commonly used for this purpose is the cone-and-plate flow chamber system, in which ECs monolayers are exposed to shear stress generated by a rotating cone (Figure 3B) [1]. Figure 4A illustrates the flow pattern of regular flow (which can be 
steady or pulsatile) created in a parallel-plate flow chamber, and also the flow pattern of irregular flow (which can be disturbed or oscillatory) created in a vertical step-flow chamber [1]. Figure 4B demonstrates various types of flow. According to the magnitude of shear stress and variation of shear stress with time, they can be categorized as static control, steady flow, pulsatile flow, and reciprocating (oscillatory) flow (Figure 4). Our group used the parallel-plate flow chamber system to investigate the effects of laminar flow on the ROS levels and ROS-related signaling in ECs. Here we briefly discuss the differential influence of regular flow vs. irregular flow on the production of ROS and NO, which may contribute to the antiatherogenic or pro-atherogenic effects.

\section{Effect of steady or pulsatile flow (regular flow)}

We and others have demonstrated that ECs exposed to steady or pulsatile flow with normal shear stress (regular flow) increased intracellular levels of ROS that enhanced the expression of Nrf2, KLF2, c-fos, superoxide dismutase (SOD), HO-1, and intracellular adhesion molecule-1 (ICAM-1) [19,48,54-56].

ECs exposed to shear stress of $20 \mathrm{dyn} / \mathrm{cm}^{2}$ had increased intracellular $\mathrm{O}_{2}{ }^{-}$[56]. Furthermore, laminar flow with shear stress of 15,25 , or $40 \mathrm{dyn} / \mathrm{cm}^{2}$ for $15 \mathrm{~min}$ led to a 0.5 - to 1.5-fold increase of intracellular ROS [19]. A concomitant increase in antioxidant activity in ECs along with ROS generation was also noticed [19]. We have also demonstrated that steady flow and pulsatile flow led to a 1-fold increase of ROS, but impulse flow triggered a small and transient increase of ROS (Figure 5). These results suggest that different flow patterns may induce ROS production to a different extent.

It has been reported that a steady or PSS produces less $\mathrm{O}_{2}{ }^{-}$than an OSS $[18,57]$. A steady high shear stress to ECs consistently suppressed ROS levels more than low shear stress [58]. ECs subjected to a prolonged laminar shear stress $\left(30\right.$ or $75 \mathrm{dyn} / \mathrm{cm}^{2}$ ) for $24 \mathrm{~h}$ reduced $\mathrm{O}_{2}$ formation and ROS levels [23,59]. Recent study using a hemodynamic Lab-on-a-chip system, however, showed no significant increase of ROS when ECs under constant shear stress $\left(30 \mathrm{dyn} / \mathrm{cm}^{2}\right)$, in contrast to the sustained increase of ROS level in ECs under physiological conditions of PSS [60]. Thus, these data are inconsistent with respect to ROS levels in ECs exposed to different flow patterns or conditions. The inconsistencies could be due to different methods used to measure ROS, prompting Dikalov et al. to recommend the use of two methods for ROS measurement [61]. In addition, different sources of ECs (vein or artery; human or bovine), different flow systems, or minor differences in cell culture and serumstarvation conditions could also be the factors contributing to these inconsistencies, as reported [62]. Moreover, the duration of flow is another factor that can affect the ROS levels. Long term flow appears to down-regulate ROS through antioxidant response mediated by antioxidant enzymes such as superoxide dismutase (SOD), catalase, glutathione peroxidase, thioredoxin, peroxiredoxins

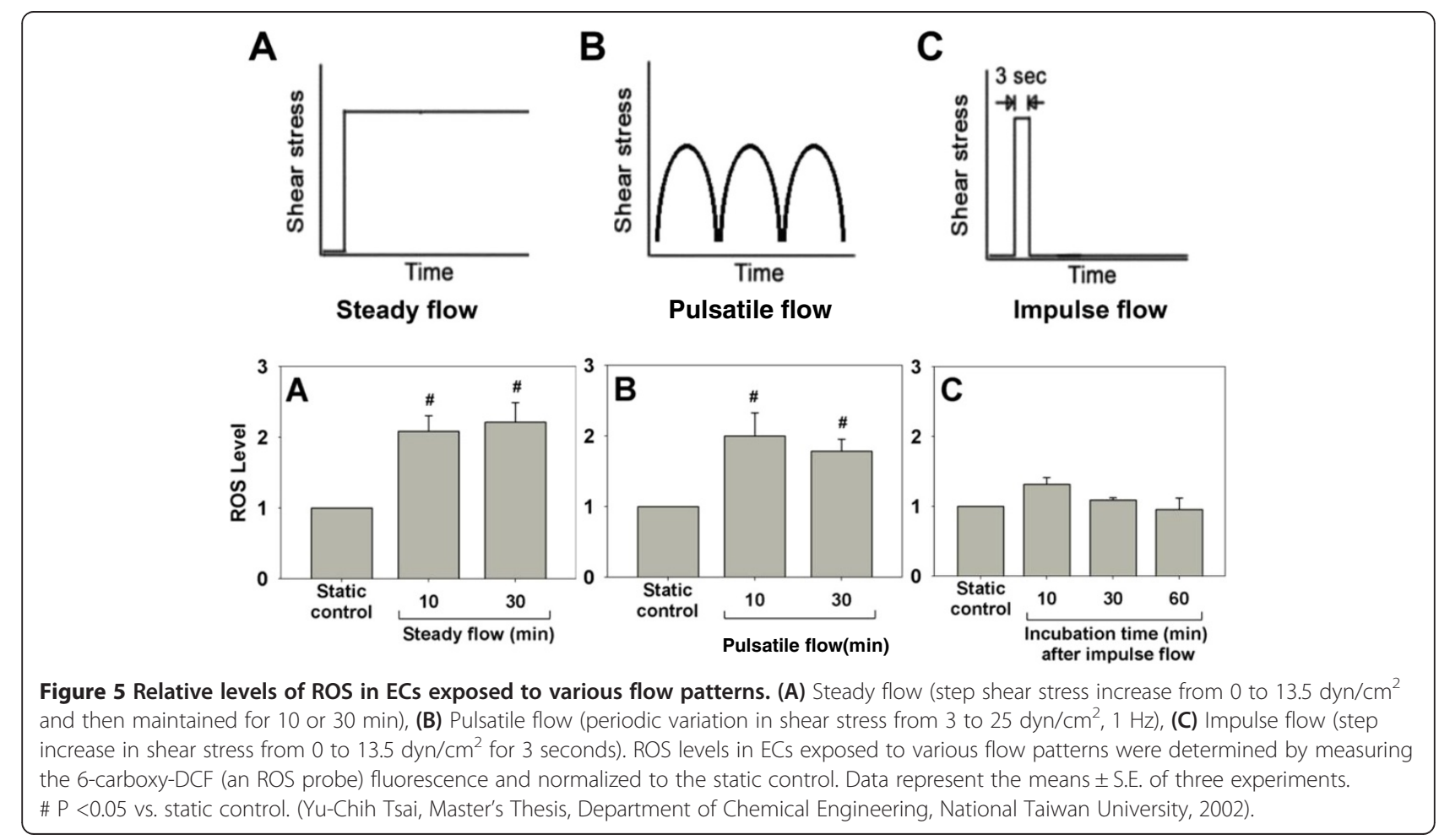


and HO-1. Despite these discrepancies, it is generally accepted that ROS become moderately elevated in ECs exposed to regular flow but that prolonged exposure to regular flow is mainly associated with an antioxidant response, unless the shear stress is abnormally high [63]. The moderately elevated ROS may act as messenger molecules in vascular adaptation to hemodynamic perturbation and thus play important roles in vascular physiology.

On the other hand, NO plays important roles in vasodilation and anti-inflammation. Many studies have examined the effects of different flow types on NO production in ECs. Frangos et al. investigated NO production in ECs exposed to three types of flow: 1) step flow, a sudden increase of shear stress from 0 to $20 \mathrm{dyn} / \mathrm{cm}^{2}$ and maintenance at $20 \mathrm{dyn} / \mathrm{cm}^{2}$; 2) ramp flow, a gradual increase in shear stress from 0 to $20 \mathrm{dyn} / \mathrm{cm}^{2}$ and maintenance at $20 \mathrm{dyn} / \mathrm{cm}^{2}$; 3) impulse flow, a 3-second pulse of $20 \mathrm{dyn} /$ $\mathrm{cm}^{2}$. Their results indicated that NO production occurs by two independent pathways. Step flow and impulse flow induced a transient burst of $\mathrm{NO}$ production that is $\mathrm{G}$ protein-dependent, and step flow and ramp flow induced sustained NO production that is G protein-independent. It is noteworthy that step flow, which contains both a rapid increase and a steady flow component, stimulates both pathways [64]. In general, NO production in ECs is continuously elevated by regular flow. NO may modify proteins and lipids and also regulate transcriptional factors and adhesion molecules expression in the vasculature. In addition, NO may react with ROS to form peroxynitrite that modulates various cellular events. However, these peroxynitrite-induced effects are limited under regular flow condition, since regular flow results in only a moderate elevation in ROS production. Even though a continuous NO production is present, the amount of peroxynitrite (and hence its influence) is quite restricted.

\section{Effect of disturbed or oscillatory flow (irregular flow)}

As mentioned, earlier clinical evidence indeed points out that atherosclerotic lesions preferentially emerge at arterial bifurcations and curvatures, where irregular flow is usually happen $[1,63,65]$. The effect of disturbed or oscillatory flow (irregular flow) on NO production in ECs has been investigated recently. An ex vivo preparation of porcine arteries exposed to the flow of a physiological solution through the vessels in the forward and reverse directions (oscillatory flow) indicated that NO concentration was significantly lower during reverse flow [66]. Furthermore, addition of $\mathrm{a} \mathrm{O}_{2}{ }^{-}$scavenger returned the $\mathrm{NO}$ concentration during reverse flow to that of forward flow. This suggests that flow reversal has a pro-atherogenic effect that may be associated with increased $\mathrm{O}_{2}{ }^{-}$production [66]. A study comparing the effects of oscillatory flow with a mean stress of $0.02 \mathrm{dyn} / \mathrm{cm}^{2}$ and pulsatile flow with a mean stress of $23 \mathrm{dyn} / \mathrm{cm}^{2}$ on ECs indicated that oscillatory flow significantly upregulated Nox4 (an NADPH oxidase subunit) and increased $\mathrm{O}_{2}$ production. In contrast, pulsatile flow upregulated eNOS expression and increased NO production [67]. These results suggest that an imbalance in $\mathrm{O}_{2}{ }^{-}$and $\mathrm{NO}$ under oscillatory flow leads to the formation of peroxynitrite, a key molecule which may trigger many pro-atherogenic events [67]. Elsewhere studies also showed altered shear triggers membrane depolarization for PI3K/Akt activation to produce ROS [68]. Taken together, the aforementioned studies suggest that shear stress with a regular flow pattern produces lower levels of ROS and more bioavailable NO (thus to be anti-atherogenic). In contrast, shear stress with an irregular flow pattern generates higher levels of ROS and less available NO that results in pro-atherogenic effects, as described in Figure 6.

\section{Influence of shear stress on ROS/NO redox signaling and downstream events}

An important feature underlying redox signaling is the reversible (covalently oxidative or nitrosative) modification of specific cysteine (Cys) thiol residues that reside within active and allosteric sites of proteins, which results in alternation of protein functions. These Redox-sensitive thiols play an essential role in cellular redox signalings and are thus associated with homeostatic maintenance. S-nitrosative modification occurs by means of oxidative reaction between $\mathrm{NO}$ and Cys thiol in the presence of an electron acceptor or through transnitrosylation from S-nitrosothiol to another Cys thiol. The oxidation or nitrosation of redox thiol is determined by the relative fluxes of ROS and NO and the proximity of the thiol-protein to the sources of ROS or NO generation. Thus, different ROS and NO production rates by various flow patterns and the subsequent ROS/RNS interplay resulting in oxidative or nitrosative modification of thiol-containing molecules can have profound effects on the signaling cascades and downstream events.

The numerous signaling pathways that are activated by flow feature ROS and $\mathrm{NO}$ as important regulators of redox signaling. The effects of shear-induced ROS/NO on redox signaling and downstream events are categorized into four aspects including kinases/phosphatase, transcriptional factors, adhesion molecules, and proteinmodifications.

\section{Effect of shear-induced ROS/NO on kinases and phosphatases}

Endogenous ROS and reactive nitrogen species (RNS) can act reversibly by altering functions of various target kinases/phosphatases. Increased activation of protein kinases such as Src, PI3K, MAPK, PKA, PKG and PKC was demonstrated by the thiol oxidation [31]. In contrast, oxidative modification of phosphatases such as 


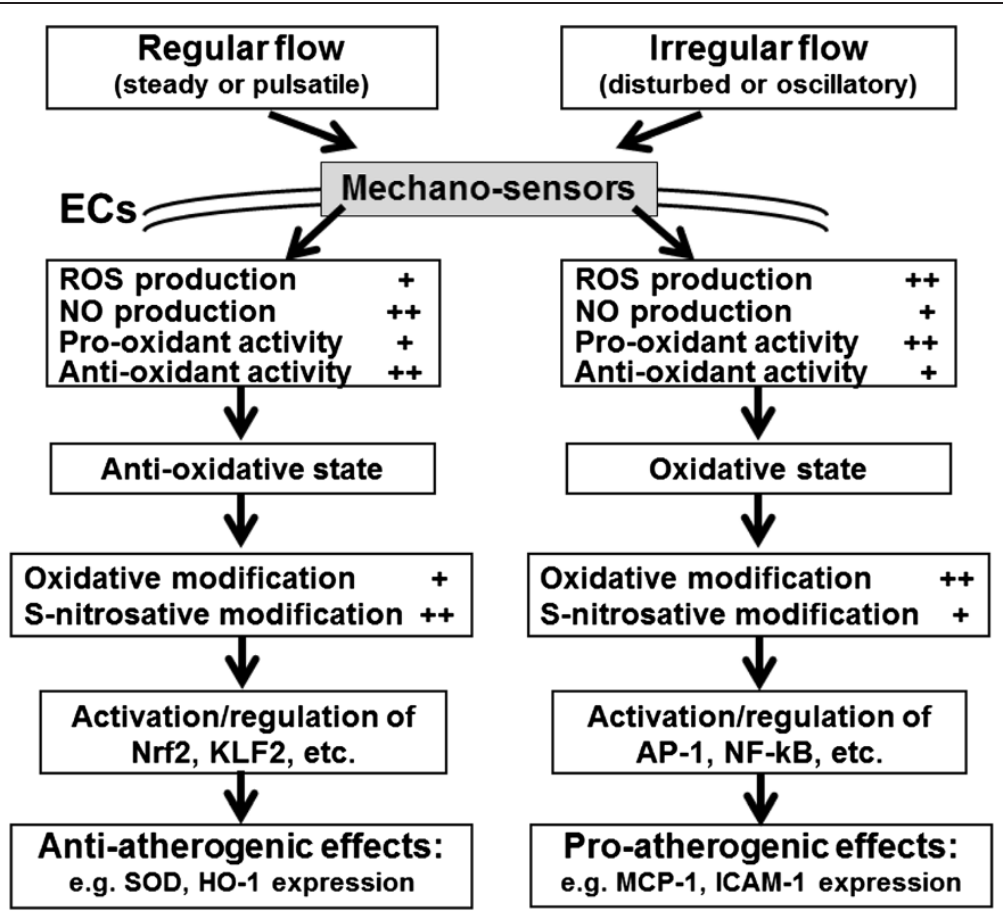

Figure 6 Pro- or anti- atherogenic effect of flow patterns through different redox signalings and genes expression. A regular flow pattern (steady or pulsatile) produces lower levels of ROS and pro-oxidant activity, yet higher NO bioavailability and anti-oxidant activity, that result in an anti-oxidative state, favoring the activation/regulation of key transcription factors such as Nrf2, KLF2 to promote anti-atherogenic environment by enhancing the expression of SOD, HO-1, etc. On the other hand, an irregular flow pattern (disturbed or oscillatory) produces higher levels of ROS and pro-oxidant activity, yet lower NO bioavailability and anti-oxidant activity, that result in an oxidative state, favoring the activation/regulation of key transcription factors such as AP-1, NF-KB for pro-atherogenic environment by enhancing the expression of MCP-1, ICAM-1, etc. ++: relatively higher; +: relatively lower.

PTEN and MAPK phosphatase suppresses their activities [31]. It is conceivable that laminar shear stress-induced ROS suppresses PTEN and MAPK phosphatase thus increasing the activation of protein kinases. Similarly, NOmediated S-nitrosation of redox thiol in protein kinases such as JNK, IKK, and Akt inhibits their protein activities [31]. Among those known phosphatases, protein tyrosine phosphatase (PTP) is highly vulnerable to this reversible oxidation $[69,70]$. PTPs, act in concert with protein tyrosine kinases to control essential cellular functions, have a highly conserved catalytic motif $(\mathrm{I} / \mathrm{V}) \mathrm{HC}\left(\mathrm{X}_{5}\right) \mathrm{R}(\mathrm{S} / \mathrm{T})$ that includes an invariant catalytic Cys residue [71]. This active site displays a low $\mathrm{pK}_{\mathrm{a}}$ and renders Cys highly susceptible to oxidation [72]. At normal physiological condition, modest ROS production following agonist stimulation transiently oxidizes the Cys to the sulfenic acid (S-OH) form [69]. Only under severe oxidation can irreversibly convert this Cys to the sulfinic $\left(\mathrm{S}-\mathrm{O}_{2} \mathrm{H}\right)$ or further to sulfonic $\left(\mathrm{S}-\mathrm{O}_{3} \mathrm{H}\right)$ acid form [72]. ECs under laminar shear stress with modest ROS production may generate the reversible sulfenic acid form of PTPs and transiently inhibits PTP activity. Intriguingly, PTPs exposed to NO elicited a highly reversible enzyme inhibition via Snitrosation (R-S-NO) [73,74]. Furthermore, cells treated with a low concentration of $\mathrm{H}_{2} \mathrm{O}_{2}$ leads to transient Snitrosation of PTP [75]. PTP inactivation by S-nitrosation also contributes to an increase of insulin sensitivity in cells [76]. The activity of Src homology region 2-domain phosphatase-2 (SHP-2), a family member of PTPs, was shown to be inhibited by shear stress [77]. Oxidative or Snitrosative modification of SHP-2 may be involved in this inhibition effect. Our studies demonstrated that ECs under steady laminar shear stress or in the presence of NO donor increased S-nitrosation of endothelial proteins [78,79]. As noted above, the catalytic Cys of PTP is vulnerable to oxidative modification, and thus there is likely a competition between S-nitrosation and oxidation on catalytic Cys of this PTP. We showed previously that a prior S-nitrosation protects PTP from irreversible oxidative modification and thus safeguard the activities of PTPs [73]. The highly reversible nature and the preemptive effect of S-nitrosation on PTPs by shear flow may be essential for modulating signaling responses during endothelial remodeling under shear stress, even in an inflammatory state (Figure 7).

Effect of shear-induced ROS/NO on transcriptional factors Earlier studies demonstrated that ROS generated by hemodynamic forces mediates the expression of $c$-fos 


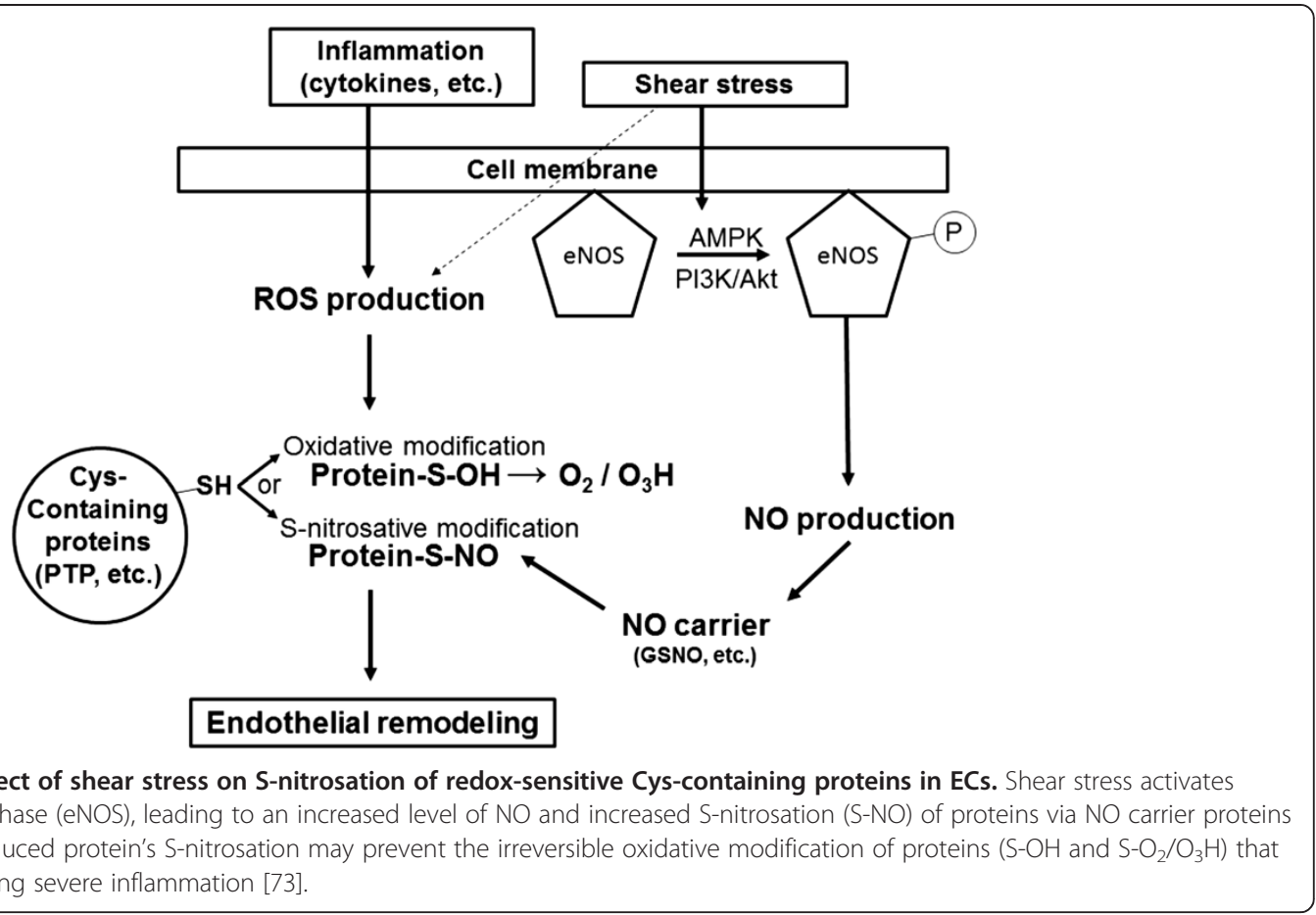

[19], egr-1 [80]. Previous studies have shown that disturbed flow leads to activation of transcription factors activation of activator protein 1 (AP-1) and nuclear factor kappa B (NFkB), whereas steady laminar flow lead to activation of Krüppel-like factor 2 (KLF2) and Nuclear factor (erythroid-derived 2)-like 2 (Nrf2) [65]. Our earlier study indicated that exposure of ECs to laminar shear stress of $12 \mathrm{dyn} / \mathrm{cm}^{2}$ induced Nrf2 nuclear translocation and this process was ROS-dependent [50]. An enhancement of the antioxidant response element (ARE)-binding activity of Nrf2 resulted in an increased expression of HO-1 [50]. These data indicate that the anti-atherogenic effect of steady laminar flow is at least partially due to the Nrf2 activation. The activation of transcription factor $\mathrm{Nrf2}$ is also regulated by $\mathrm{H}_{2} \mathrm{O}_{2}$ and $\mathrm{NO}$ via the oxidation of Keap1 (a repressor of the Nrf2) at its critical cysteine residue, leading to Keap1 inactivation and thus allowing translocation of Nrf2 to the nucleus for initiating transcription of target genes [81]. Taken together, these findings support the concept of redox regulation of signaling pathways in flow-treated ECs, as proposed in Figure 6. However, there are still many inconsistencies among various studies on redox-responsive transcription systems, mainly due to the complexity and spatiotemporal factor of the redox-sensitive systems [82]. Fluid shear stress also induces transcriptional factors, such as KLF2, which upregulate eNOS expression [47-49]. Steady or PSS markedly activates Nrf2 and induces Nrf2-regulated antioxidant genes, such as heme oxygenase- 1 and thioredoxin reductase- 1 (TrxR1), and this reduces the level of intracellular $\mathrm{O}_{2}{ }^{-}$, thereby increasing the level of bioavailability NO [50-52].

\section{Effect of shear-induced ROS/NO on adhesion molecules and others}

Earlier studies demonstrated that a modest increase of ROS mediated cyclic strain-induced expression of monocyte chemotactic protein-1 (MCP-1), intercellular adhesion molecule-1 (ICAM-1) [80,83] and shear stress-induced intercellular adhesion molecule-1 (ICAM-1) [56]. Oscillatory shear stress stimulated adhesion molecules (VCAM-1, ICAM-1 and E-selectin) expression in ECs and this upregulation could be suppressed in the presence of antioxidant (NAC), indicating oscillatory shear stress-induced signals are redox sensitive [84]. Shear stress increases ICAM-1 but decreases VCAM-1 and E-selectin expression induced by TNF $\alpha$, indicating differential roles of shear stress in modulating TNF $\alpha$-induced expression of adhesion molecules [85]. Using parallel-plate flow system, ECs cocultured with smooth muscle cells induced ICAM-1, VCAM-2 and Eselectin expression. However, these coculture effects are inhibited by shear stress [86]. High shear stress also suppressed tumor cell-ECs coculture-induced adhesion molecule expression [87]. To study the hemodynamic influence on the aortic valve inflammation, aortic surface of porcine aortic valve leaflets were exposed for 48 hours to pulsatile or oscillatory shear stress. Surprisingly, pulsatile shear stress, but not oscillatory shear stress, increased expression of the VCAM-1 and ICAM-1 [88]. In contrast, NO donor treatment reduced TNF $\alpha$-induced VCAM-1 
and ICAM-1 expression in ECs [89]. Indeed, shear flow increases NO-mediated S-nitrosation of proteins in ECs [78]. How this shear-induced S-nitrosative proteins modulating endothelial responses to cytokines remain to be determined. Structural proteins such as actin and integrin alpha6 have been shown to be S-nitrosated and thioredoxin reductase is responsible for actin denitrosation [90,91]. S-nitrosation of actin accelerates actin filament turnover and $\mathrm{S}$-nitrosation of integrin alpha6 increases cancer cell migration $[90,91]$. It remains to be determined whether shear stress increases S-nitrosation of these structural proteins and modulates endothelial remodeling under flow conditions.

\section{Effect of shear-induced ROS/NO on protein-modification}

Many Cys-containing proteins such as signaling molecules and transcriptional factors are potential targets that undergo a range of ROS-dependent or reactive nitrogen species (RNS)-dependent oxidative and nitrosative modifications of this Cys-containig proteins. Physiologically, NO through S-nitrosation of proteins regulates numerous cellular responses. $\mathrm{NO}$ exerts as an antioxidant by inhibiting NADPH oxidase activity via S-nitrosation [92]. $\mathrm{NO}$ was shown to promote the ROS scavenging activity of thioredoxin-1 via S-nitrosation on Cys69 residue [93,94]. Indeed, ECs under physiological shear stress increased protein S-nitrosylation [78,95] independent of cGMPdependent signaling. In contrast, ECs with TNF $\alpha$ and mild oxidized low density lipoprotein (LDL) treatment reduced S-nitrosation [96]. Early researches demonstrated that AP-1 activity was altered by S-nitrosylation [97] and also by oxidation of Cys residues in AP-1 [98]. Furthermore, $\mathrm{H}_{2} \mathrm{O}_{2}$ treatment inhibited AP-1 activity and decreased eNOS promoter activity [99]. NFkB, AP-1, and p53 all contain reactive thiols in their DNA binding regions, the modification of which alters their binding to DNA. Thus, the dynamic interplay of ROS and $\mathrm{NO}$ and their oxidative and S-nitrosative modification of signaling molecules and/ or regulatory protein thiols may be responsible for the consequent endothelial physiology under different flow conditions. The ROS and NO production rates in ECs under different flow patterns, leading to the differential activation/regulation of these thiol-proteins and thus results in anti-atherogenic (e.g. SOD, HO-1 expression) or pro-atherogenic effects (e.g. MCP-1, ICAM-1 expression) via different signaling pathways regulated by key transcription factors such as $\mathrm{Nrf} 2$, KLF2, AP-1, NFKB, etc.

\section{Effects of flow patterns on redox signaling and gene expressions}

As mentioned earlier, the geometric structure of the vascular tree comprises straight, curved, branched, and many other complex features. In vivo evidence indicates that the atherosclerotic lesions preferentially localize at bends and bifurcations in the arterial tree with irregular flow patterns (disturbed with low and reciprocating (oscillatory) shear regions) [6]. However, no signs of atherosclerotic lesions appear in the straight part of the arterial tree where regular flow patterns (laminar with physiological shear stresses) predominate. Many studies have demonstrated that regular flow causes activation and regulation of anti-atherogenic and anti-inflammation genes, whereas irregular flow increases transcription of proatherogenic genes $[1,63,65]$.

Based on available evidence and our previous discussion, the differential cellular response to different flow patterns may be explained by Figure 6: A regular flow pattern produces lower levels of ROS and higher NO bioavailability, leading to an anti-oxidative state and thus creating an anti-atherogenic environment via the expression of SOD, HO-1, etc. Conversely, an irregular flow pattern results in higher levels of ROS and yet lower NO bioavailability, giving rise to oxidative state and thus triggering pro-atherogenic effects through the expression of MCP-1, ICAM-1, etc. The irregular flow-induced low NO bioavailability is partly caused by the reaction of ROS with NO to form peroxynitrite, a key molecule which may initiate many pro-atherogenic events (Figure 6).

\section{Effect of shear stress on S-nitrosation}

Increased NO production by eNOS activation in ECs under shear stress modulates various cellular processes that are essential for endothelial integrity. S-nitrosation involved in posttranslational regulation of many proteins that modulate cardiovascular function [14,100-103]. eNOS-derived NO selectively S-nitrosates many endothelial proteins and modulate diverse cell processes [104], including migration [105], permeability [106,107], oxidative stress [92,108], aging [109], and inflammation $[110,111]$. Current methods for detecting S-nitrosated proteins involve three key steps: 1) blocking free Cys thiols $(-\mathrm{SH})$ by alkylation reagents [such as methyl methanethiosulfonate (MMTS) and iodoacetamide (IAM)] [101,112]. 2) Reduction of (S-NO) to free thiol (-SH) by ascorbate, and 3) free thiol is then labeled by biotin or CyDye (CyDye switch) [78,95,101]. After protein separation by two-dimensional gel electrophoresis (2-DE), the S-nitrosated proteins were subsequently analyzed and determined by LC-MS/MS. Using CyDye switch method coupled with two-dimensional gel electrophoresis, we demonstrated that shear induced eNOS activation in ECs led to S-nitrosation of more than one hundred proteins $[78,79]$. Several of which may be essential for endothelial remodeling. Interestingly, S-nitrosation may, by providing a negative feedback that limits eNOS activation, also affect vascular tone. S-nitrosation disrupts eNOS dimmers, leading to decreased eNOS activity [113,114]. This is supported by the fact that eNOS in resting cells is S- 
nitrosated; treatment with eNOS agonist vascular endothelial growth factor (VEGF) causes rapid denitrosation and eNOS activation although the mechanisms of Snitrosation/denitrosation are unclear [115]. Furthermore, S-nitrosation of chaperone heat shock protein (Hsp90) suppresses its stimulatory effect on eNOS activity [116]. Thus, eNOS-derived NO production in ECs is regulated via the S-nitrosation/denitrosation of eNOS and eNOS dependent regulatory proteins, although the detailed control mechanisms are unclear.

We and others have shown that shear induces Snitrosylation of endothelial proteins [78,95]. Presumably such changes drive vascular remodeling with flow. Shear stress-induced $\mathrm{S}$-nitrosation is possibly dependent on the magnitude of the shear stress, consistent with the notion that endothelial NO production is proportional to the magnitude of the shear stress $[78,95]$. Importantly, eNOS-derived NO-mediated S-nitrosation is likely to be restricted to regions where eNOS are localized because higher concentration of $\mathrm{NO}$ is required to sustain protein S-nitrosation [104]. Intriguingly, in ECs treated with a NO donor (S-nitroso-N-acetylpenicillamine, SNAP) only a subset of the proteins became S-nitrosated [78]. This selective S-nitrosation in sheared ECs may be a consequence of a spatiotemporal partitioning of eNOS/ $\mathrm{NO}$ and the vicinity of its target proteins within cellular compartments.

Recent studies indicate that protein S-nitrosation status in vivo is quite complex and involves a precisely regulated equilibrium between S-nitrosation and denitrosation reactions. These processes involve transnitrosation reactions between a variety of peptides and proteins. The consequent protein denitrosation can be critical in S-nitrosationmediated signal mechanisms [117]. Whether shear flow and/or various flow patterns affect the equilibrium between S-nitrosation/denitrosation remains to be determined.

\section{Influence of shear stress on oxidative stress-induced inflammation of endothelium}

ROS act as second messengers to transduce the shear signal and are thus important for the eventual physiological or pathophysiological response to shear. Under conditions of inflammation, the elevated ROS alter the NO/ROS equilibrium and the antioxidant status within cells. However, steady laminar flow exerts atheroprotection to ECs [1]. Indeed, laminar shear stress attenuates interleukin 6-induced JAK2/STAT3 activation [118] and interferon- $\gamma$-induced STAT1 activation in a shear magnitude-dependent manner [119]. Presumably, shear stress by suppressing elevations in ROS increases NO bioavailability and thus NO-mediated signaling, including S-nitrosation of regulatory proteins in ECs.

Although many S-nitrosated proteins have been identified in the cardiovascular system [120], and many such proteins are abundant and have been shown to be $\mathrm{S}$ nitrosated in ECs under shear stress, the extent to which they may be protective is yet to be elucidated [95]. Studies have demonstrated S-NO-mediated suppression of NFkB-dependent expression of proinflammatory cytokines and adhesion molecules [107,118]. Overall, it is very likely that S-nitrosation of lower abundance signaling proteins play essential roles in atheroprotection. More targeted approach to identify S-nitrosated candidate proteins in ECs is needed. It is anticipated that the anti-inflammatory actions of $\mathrm{NO}$ via $\mathrm{S}$-nitrosation is relevant across a range of vascular pathologies initiated by defective S-nitrosation. Since shear stress-induced activation of ECs is associated with S-nitrosation of many proteins, it is not surprising that an increase in flow and shear stress enhance eNOS expression and NO production play a crucial role in the prevention or retardation of progression of vascular diseases.

\section{Conclusions}

It is now well established that low amounts of ROS are essential for normal cellular function, and increased ROS production contributes to vascular oxidative stress. ROS production varies under different flow patterns and conditions and this differential production modulates endothelial gene expression through complex mechanotransduction processes, to induce atheroprotective (laminar flow) or atherogenic (disturbed flow) endothelial phenotype and formation of an early atherosclerotic plaque. The redox regulation of shear signal also involves $\mathrm{NO}$; indeed there is a very important role for $\mathrm{ROS} / \mathrm{NO}$ interactions and Snitrosation in mechano-signaling. The bioavailability of NO, S-nitrosation of transcription factors and other signaling proteins may be important determinants of vascular endothelial homeostasis under various flow conditions. The dynamic nature and consequences of oxidative and S-nitrosative proteins in sheared endothelial cells and its relevance to the atheroprotection are important topics for future studies.

\section{Abbreviations}

AP-1: Activator protein-1; ARE: Antioxidant response element; ECs: Endothelial cells; eNOS: Endothelial cell NO synthase; FAK: Focal adhesion kinase; GPCR: G protein-coupled receptor; HO-1: Heme oxygenase1; ICAM-1: Intracellular adhesion molecule-1; KLF2: Krüppel-like factor 2; LDL: Low density lipoprotein; MCP-1: Monocyte chemotactic protein-1; NF-kB: Nuclear factor kappa B; NO: Nitric oxide; Nox: NADPH oxidase; Nrf2: Nuclear factor (erythroid-derived 2)-like 2; OSS: Oscillatory shear stress; PSS: Pulsatile shear stress; PTP: Protein tyrosine phosphatase; RNS: Reactive nitrogen species; ROS: Reactive oxygen species; SHP-2: Src homology region 2-domain phosphatase-2; SOD: Superoxide dismutase; TrxR1: Thioredoxin reductase-1; VCAM-1: Vascular cell adhesion molecule-1; VEGF: Vascular endothelial growth factor; XO: Xanthine oxidase.

\section{Competing interests}

The authors declare that they have no competing interests. 


\section{Authors' contributions}

$\mathrm{HJH}$ and DLW collected information, organized and wrote this manuscript, and also designed conceptual figures. CAL, BH, and AHHT provided helpful suggestions and information. All authors read and approved the final manuscript.

\section{Acknowledgements}

We thank Miss Chia-Yu Hsiao for preparing the figures and diagrams of this manuscript. We also thank Drs. A.B. Fisher and Shampa Chatterjee, University of Pennsylvania for their valuable suggestions and editing. This work was generously supported by the National Science Council, Taiwan (grant numbers: NSC100-2221-E-002-113-MY2 (to HJ Hsieh) \& NSC 99-2320-B-001010-MY3 (to DL Wang)).

\section{Author details}

'Department of Chemical Engineering, National Taiwan University, Taipei 10617, Taiwan. ${ }^{2}$ Institute of Biomedical Sciences, Academia Sinica, Taipei 11529, Taiwan. ${ }^{3}$ Department of Biomedical Science and Environmental Biology, College of Life Science, Kaohsiung Medical University, Kaohsiung 80708, Taiwan. ${ }^{4}$ Institute of Medical Sciences, College of Medicine, Tzu-Ch University, Hualien 97004, Taiwan.

Received: 3 October 2013 Accepted: 2 January 2014

Published: 13 January 2014

\section{References}

1. Chiu JJ, Chien S: Effects of disturbed flow on vascular endothelium: pathophysiological basis and clinical perspectives. Physiol Rev 2011, 91:327-387.

2. Berk $B C$ : Atheroprotective signaling mechanisms activated by steady laminar flow in endothelial cells. Circulation 2008, 117:1082-1089.

3. Davies PF: Flow-mediated endothelial mechanotransduction. Physiol Rev 1995, 75:519-560

4. Pan S: Molecular mechanisms responsible for the atheroprotective effects of laminar shear stress. Antioxid Redox Signal 2009, 11:1669-1682.

5. Chien S: Mechanotransduction and endothelial cell homeostasis: the wisdom of the cell. Am J Physiol Heart Circ Physiol 2007, 292:H1209-1224.

6. VanderLaan PA, Reardon CA, Getz GS: Site specificity of atherosclerosis: site-selective responses to atherosclerotic modulators. Arterioscler Thromb Vasc Biol 2004, 24:12-22.

7. Hahn C, Schwartz MA: The role of cellular adaptation to mechanical forces in atherosclerosis. Arterioscler Thromb Vasc Biol 2008, 28:2101-2107.

8. Birukov KG: Cyclic stretch, reactive oxygen species, and vascular remodeling. Antioxid Redox Signal 2009, 11:1651-1667.

9. Matlung HL, Bakker EN, VanBavel E: Shear stress, reactive oxygen species, and arterial structure and function. Antioxid Redox Signal 2009, 11:1699-1709.

10. Cai H, Harrison DG: Endothelial dysfunction in cardiovascular diseases: the role of oxidant stress. Circ Res 2000, 87:840-844.

11. Stocker R, Keaney JF Jr: Role of oxidative modifications in atherosclerosis. Physiol Rev 2004, 84:1381-1478.

12. Villacorta L, Chang L, Salvatore SR, Ichikawa T, Zhang J, Petrovic-Djergovic D, Jia L, Carlsen H, Schopfer FJ, Freeman BA, Chen YE: Electrophilic nitro-fatty acids inhibit vascular inflammation by disrupting LPS-dependent TLR4 signalling in lipid rafts. Cardiovasc Res 2013, 98:116-124.

13. Cui T, Schopfer FJ, Zhang J, Chen K, Ichikawa T, Baker PR, Batthyany C, Chacko BK, Feng $X$, Patel RP, et al: Nitrated fatty acids: Endogenous antiinflammatory signaling mediators. J Biol Chem 2006, 281:35686-35698.

14. Hare JM, Stamler JS: NO/redox disequilibrium in the failing heart and cardiovascular system. J Clin Invest 2005, 115:509-517.

15. Landmesser U, Spiekermann S, Dikalov S, Tatge H, Wilke R, Kohler C, Harrison DG, Hornig B, Drexler H: Vascular oxidative stress and endothelial dysfunction in patients with chronic heart failure: role of xanthineoxidase and extracellular superoxide dismutase. Circulation 2002, 106:3073-3078.

16. Landmesser U, Spiekermann S, Preuss C, Sorrentino S, Fischer D, Manes C, Mueller $\mathrm{M}$, Drexler $\mathrm{H}$ : Angiotensin II induces endothelial xanthine oxidase activation: role for endothelial dysfunction in patients with coronary disease. Arterioscler Thromb Vasc Biol 2007, 27:943-948.

17. Lassegue B, San Martin A, Griendling KK: Biochemistry, physiology, and pathophysiology of NADPH oxidases in the cardiovascular system. Circ Res 2012, 110:1364-1390.
18. De Keulenaer GW, Chappell DC, Ishizaka N, Nerem RM, Alexander RW, Griendling KK: Oscillatory and steady laminar shear stress differentially affect human endothelial redox state: role of a superoxide-producing NADH oxidase. Circ Res 1998, 82:1094-1101.

19. Hsieh HJ, Cheng CC, WU ST, Chiu JJ, Wung BS, Wang DL: Increase of reactive oxygen species (ROS) in endothelial cells by shear flow and involvement of ROS in shear-induced c-fos expression. J Cell Physiol 1998, 175:156-162.

20. Godbole AS, Lu X, Guo X, Kassab GS: NADPH oxidase has a directional response to shear stress. Am J Physiol Heart Circ Physiol 2009, 296:H152-158.

21. Takabe W, Jen N, Ai L, Hamilton R, Wang S, Holmes K, Dharbandi F, Khalsa B, Bressler S, Barr ML, et al: Oscillatory shear stress induces mitochondrial superoxide production: implication of NADPH oxidase and c-Jun NH2terminal kinase signaling. Antioxid Redox Signal 2011, 15:1379-1388.

22. Duerrschmidt N, Stielow C, Muller G, Pagano PJ, Morawietz H: NO-mediated regulation of $\mathrm{NAD}(\mathrm{P}) \mathrm{H}$ oxidase by laminar shear stress in human endothelial cells. J Physiol 2006, 576:557-567.

23. Goettsch C, Goettsch W, Brux M, Haschke C, Brunssen C, Muller G, Bornstein SR, Duerrschmidt N, Wagner AH, Morawietz H: Arterial flow reduces oxidative stress via an antioxidant response element and Oct-1 binding site within the NADPH oxidase 4 promoter in endothelial cells. Basic Res Cardiol 2011, 106:551-561.

24. Huang A, Sun D, Kaley G, Koller A: Superoxide released to high intraarteriolar pressure reduces nitric oxide-mediated shear stress- and agonist-induced dilations. Circ Res 1998, 83:960-965.

25. Sorescu GP, Song H, Tressel SL, Hwang J, Dikalov S, Smith DA, Boyd NL, Platt MO, Lassegue B, Griendling KK, Jo H: Bone morphogenic protein 4 produced in endothelial cells by oscillatory shear stress induces monocyte adhesion by stimulating reactive oxygen species production from a nox1-based NADPH oxidase. Circ Res 2004, 95:773-779.

26. Ali MH, Pearlstein DP, Mathieu CE, Schumacker PT: Mitochondrial requirement for endothelial responses to cyclic strain: implications for mechanotransduction. Am J Physiol Lung Cell Mol Physiol 2004, 287:L486-496.

27. Liu Y, Zhao H, Li H, Kalyanaraman B, Nicolosi AC, Gutterman DD: Mitochondrial sources of $\mathrm{H} 2 \mathrm{O} 2$ generation play a key role in flow-mediated dilation in human coronary resistance arteries. Circ Res 2003, 93:573-580.

28. Han Z, Chen YR, Jones Cl 3rd, Meenakshisundaram G, Zweier JL, Alevriadou BR: Shear-induced reactive nitrogen species inhibit mitochondrial respiratory complex activities in cultured vascular endothelial cells. Am J Physiol Cell Physiol 2007, 292:C1103-1112.

29. Doehner W, Schoene N, Rauchhaus M, Leyva-Leon F, Pavitt DV, Reaveley DA, Schuler G, Coats AJ, Anker SD, Hambrecht R: Effects of xanthine oxidase inhibition with allopurinol on endothelial function and peripheral blood flow in hyperuricemic patients with chronic heart failure: results from 2 placebo-controlled studies. Circulation 2002, 105:2619-2624.

30. McNally JS, Davis ME, Giddens DP, Saha A, Hwang J, Dikalov S, Jo H, Harrison DG: Role of xanthine oxidoreductase and $\mathrm{NAD}(\mathrm{P}) \mathrm{H}$ oxidase in endothelial superoxide production in response to oscillatory shear stress. Am J Physiol Heart Circ Physiol 2003, 285:H2290-2297.

31. Thomas SR, Witting PK, Drummond GR: Redox control of endothelial function and dysfunction: molecular mechanisms and therapeutic opportunities. Antioxid Redox Signal 2008, 10:1713-1765.

32. Youn JY, Gao L, Cai H: The p47phox- and NADPH oxidase organiser 1 (NOXO1)-dependent activation of NADPH oxidase 1 (NOX1) mediates endothelial nitric oxide synthase (eNOS) uncoupling and endothelial dysfunction in a streptozotocin-induced murine model of diabetes. Diabetologia 2012, 55:2069-2079.

33. Dikalova AE, Gongora MC, Harrison DG, Lambeth JD, Dikalov S, Griendling KK: Upregulation of Nox1 in vascular smooth muscle leads to impaired endothelium-dependent relaxation via eNOS uncoupling. Am J Physiol Heart Circ Physiol 2010, 299:H673-679.

34. Yang YM, Huang A, Kaley G, Sun D: eNOS uncoupling and endothelial dysfunction in aged vessels. Am J Physiol Heart Circ Physiol 2009, 297:H1829-1836.

35. Uematsu M, Ohara Y, Navas JP, Nishida K, Murphy TJ, Alexander RW, Nerem RM, Harrison DG: Regulation of endothelial cell nitric oxide synthase mRNA expression by shear stress. Am J Physiol 1995, 269:C1371-1378.

36. Sessa WC: eNOS at a glance. J Cell Sci 2004, 117:2427-2429.

37. Boo YC, Jo H: Flow-dependent regulation of endothelial nitric oxide synthase: role of protein kinases. Am J Physiol Cell Physiol 2003, 285:C499-508. 
38. Dimmeler S, Fleming I, Fisslthaler B, Hermann C, Busse R, Zeiher AM: Activation of nitric oxide synthase in endothelial cells by Akt-dependent phosphorylation. Nature 1999, 399:601-605

39. Boo YC, Hwang J, Sykes M, Michell BJ, Kemp BE, Lum H, Jo H: Shear stress stimulates phosphorylation of eNOS at Ser(635) by a protein kinase Adependent mechanism. Am J Physiol Heart Circ Physiol 2002, 283:H1819-1828.

40. Roy D, Belsham DD: Melatonin receptor activation regulates $\mathrm{GnRH}$ gene expression and secretion in GT1-7 GnRH neurons. Signal transduction mechanisms. J Biol Chem 2002, 277:251-258.

41. Li Y, Ouyang J, Zheng H, Yu Z, Wang B: [The role of caveolae in shear stress-induced endothelial nitric-oxide synthase activation]. Sheng Wu Yi Xue Gong Cheng Xue Za Zhi 2005, 22:1020-1023.

42. Kumar S, Sud N, Fonseca FV, Hou Y, Black SM: Shear stress stimulates nitric oxide signaling in pulmonary arterial endothelial cells via a reduction in catalase activity: role of protein kinase C delta. Am J Physiol Lung Cell Mol Physiol 2010, 298:L105-116.

43. Chen Z, Peng IC, Sun W, Su MI, Hsu PH, Fu Y, Zhu Y, DeFea K, Pan S, Tsai $M D$, Shyy JY: AMP-activated protein kinase functionally phosphorylates endothelial nitric oxide synthase Ser633. Circ Res 2009, 104:496-505.

44. Zhang YJ, Lee TS, Kolb EM, Sun K, Lu X, Sladek FM, Kassab GS, Garland T, Shyy JYJ: AMP-activated protein kinase is involved in endothelial NO synthase activation in response to shear stress. Arteriosd Throm Vas 2006, 26:1281-1287.

45. Mattagajasingh I, Kim CS, Naqvi A, Yamamori T, Hoffman TA, Jung SB, DeRicco J, Kasuno K, Irani K: SIRT1 promotes endothelium-dependent vascular relaxation by activating endothelial nitric oxide synthase. Proc Natl Acad Sci USA 2007, 104:14855-14860.

46. Chen Z, Peng IC, Cui X, Li YS, Chien S, Shyy JY: Shear stress, SIRT1, and vascular homeostasis. Proc Natl Acad Sci U S A 2010, 107:10268-10273.

47. SenBanerjee $S$, Lin ZY, Atkins GB, Greif DM, Rao RM, Kumar A, Feinberg MW, Chen ZP, Simon DI, Luscinskas FW, et al: KLF2 is a novel transcriptional regulator of endothelial proinflammatory activation. J Exp Med 2004, 199:1305-1315.

48. Dekker RJ, van Soest S, Fontijn RD, Salamanca S, de Groot PG, VanBavel E, Pannekoek H, Horrevoets AJG: Prolonged fluid shear stress induces a distinct set of endothelial cell genes, most specifically lung Krüppel-like factor (KLF2). Blood 2002, 100:1689-1698.

49. Wang WY, $\mathrm{Ha}$ CH, Jhun BS, Wong C, Jain MK, Jin ZG: Fluid shear stress stimulates phosphorylation-dependent nuclear export of HDAC5 and mediates expression of KLF2 and eNOS. Blood 2010, 115:2971-2979.

50. Hsieh CY, Hsiao HY, Wu WY, Liu CA, Tsai YC, Chao YJ, Wang DL, Hsieh HJ: Regulation of shear-induced nuclear translocation of the Nrf2 transcription factor in endothelial cells. J Biomed Sci 2009, 16.

51. Takabe W, Warabi E, Noguchi N: Anti-Atherogenic Effect of Laminar Shear Stress via Nrf2 Activation. Antioxid Redox Sign 2011, 15:1415-1426.

52. Warabi E, Takabe W, Minami T, Inoue K, Itoh K, Yamamoto M, Ishii T, Kodama T, Noguchi N: Shear stress stabilizes NF-E2-related factor 2 and induces antioxidant genes in endothelial cells: role of reactive oxygen/ nitrogen species. Free Radic Biol Med 2007, 42:260-269.

53. Frangos JA, Eskin SG, McIntire LV, Ives CL: Flow effects on prostacyclin production by cultured human endothelial cells. Science 1985, 227:1477-1479.

54. Chen XL, Varner SE, Rao AS, Grey JY, Thomas S, Cook CK, Wasserman MA, Medford RM, Jaiswal AK, Kunsch C: Laminar flow induction of antioxidant response element-mediated genes in endothelial cells - A novel antiinflammatory mechanism. J Biol Chem 2003, 278:703-711.

55. Inoue N, Ramasamy S, Fukai T, Nerem RM, Harrison DG: Shear stress modulates expression of $\mathrm{Cu} / \mathrm{Zn}$ superoxide dismutase in human aortic endothelial cells. Circ Res 1996, 79:32-37.

56. Chiu JJ, Wung BS, Shyy JY, Hsieh HJ, Wang DL: Reactive oxygen species are involved in shear stress-induced intercellular adhesion molecule-1 expression in endothelial cells. Arterioscler Thromb Vasc Biol 1997, 17:3570-3577

57. Hwang J, Saha A, Boo YC, Sorescu GP, McNally JS, Holland SM, Dikalov S, Giddens DP, Griendling KK, Harrison DG, Jo H: Oscillatory shear stress stimulates endothelial production of O2- from p47phox-dependent NAD (P)H oxidases, leading to monocyte adhesion. J Biol Chem 2003, 278:47291-47298.

58. Mohan S, Koyoma K, Thangasamy A, Nakano H, Glickman RD, Mohan N: Low shear stress preferentially enhances IKK activity through selective sources of ROS for persistent activation of NF-kappa B in endothelial cells. Am J Physiol-Cell Ph 2007, 292:C362-C371.
59. White SJ, Hayes EM, Lehoux S, Jeremy JY, Horrevoets AJ, Newby AC Characterization of the differential response of endothelial cells exposed to normal and elevated laminar shear stress. J Cell Physio/ 2011, 226:2841-2848.

60. Chin LK, Yu JQ, Fu Y, Yu T, Liu AQ, Luo KQ: Production of reactive oxygen species in endothelial cells under different pulsatile shear stresses and glucose concentrations. Lab Chip 2011, 11:1856-1863.

61. Dikalov S, Griendling KK, Harrison DG: Measurement of reactive oxygen species in cardiovascular studies. Hypertension 2007, 49:717-727.

62. Bao XP, Lu CY, Frangos JA: Mechanism of temporal gradients in shearinduced ERK1/2 activation and proliferation in endothelial cells. Am J Physiol-Heart C 2001, 281:H22-H29.

63. Lehoux S: Redox signalling in vascular responses to shear and stretch. Cardiovasc Res 2006, 71:269-279.

64. Frangos JA, Huang TY, Clark CB: Steady shear and step changes in shear stimulate endothelium via independent mechanisms-superposition of transient and sustained nitric oxide production. Biochem Biophys Res Commun 1996, 224:660-665.

65. Nigro P, Abe J, Berk BC: Flow shear stress and atherosclerosis: a matter of site specificity. Antioxid Redox Signal 2011, 15:1405-1414.

66. Lu X, Kassab GS: Nitric oxide is significantly reduced in ex vivo porcine arteries during reverse flow because of increased superoxide production. J Physiol Lond 2004, 561:575-582.

67. Hsiai TK, Hwang J, Barr ML, Correa A, Hamilton R, Alavi M, Rouhanizadeh M, Cadenas E, Hazen SL: Hemodynamics influences vascular peroxynitrite formation: Implication for low-density lipoprotein apo-B-100 nitration. Free Radical Bio Med 2007, 42:519-529.

68. Chatterjee S, Browning EA, Hong N, DeBolt K, Sorokina EM, Liu W, Birnbaum $\mathrm{MJ}$, Fisher AB: Membrane depolarization is the trigger for PI3K/Akt activation and leads to the generation of ROS. Am J Physiol Heart Circ Physiol 2012, 302:H105-114.

69. Meng TC, Fukada T, Tonks NK: Reversible oxidation and inactivation of protein tyrosine phosphatases in vivo. Mol Cell 2002, 9:387-399.

70. Kwon J, Lee SR, Yang KS, Ahn Y, Kim YJ, Stadtman ER, Rhee SG: Reversible oxidation and inactivation of the tumor suppressor PTEN in cells stimulated with peptide growth factors. Proc Natl Acad Sci USA 2004 101:16419-16424

71. Andersen JN, Mortensen $\mathrm{OH}$, Peters GH, Drake PG, Iversen LF, Olsen OH Jansen PG, Andersen HS, Tonks NK, Moller NPH: Structural and evolutionary relationships among protein tyrosine phosphatase domains. Mol Cell Biol 2001, 21:7117-7136.

72. Rhee SG, Bae YS, Lee SR, Kwon J: Hydrogen peroxide: a key messenger that modulates protein phosphorylation through cysteine oxidation. SCi STKE 2000, 2000:pe1.

73. Chen YY, Chu HM, Pan KT, Teng CH, Wang DL, Wang AH, Khoo KH, Meng $\mathrm{TC}$ : Cysteine S-nitrosylation protects protein-tyrosine phosphatase $1 \mathrm{~B}$ against oxidation-induced permanent inactivation. J Biol Chem 2008, 283:35265-35272.

74. Yu CX, Li S, Whorton AR: Redox regulation of PTEN by S-nitrosothiols. Mol Pharmacol 2005, 68:847-854.

75. Barrett DM, Black SM, Todor H, Schmidt-Ullrich RK, Dawson KS, Mikkelsen RB: Inhibition of protein-tyrosine phosphatases by mild oxidative stresses is dependent on S-nitrosylation. J Biol Chem 2005, 280:14453-14461.

76. Hsu MF, Meng TC: Enhancement of insulin responsiveness by nitric oxide-mediated inactivation of protein-tyrosine phosphatases. J Biol Chem 2010, 285:7919-7928

77. Lerner-Marmarosh N, Yoshizumi M, Che WY, Surapisitchat J, Kawakatsu H, Akaike M, Ding B, Huang QH, Yan C, Berk BC, Abe J: Inhibition of tumor necrosis factor-alpha-induced SHP-2 phosphatase activity by shear stress - A mechanism to reduce endothelial inflammation. Arteriosd Throm Vas 2003, 23:1775-1781.

78. Huang B, Chen SC, Wang DL: Shear flow increases S-nitrosylation of proteins in endothelial cells. Cardiovasc Res 2009, 83:536-546.

79. Huang B, Liao CL, Lin YP, Chen SC, Wang DL: S-nitrosoproteome in endothelial cells revealed by a modified biotin switch approach coupled with Western blot-based two-dimensional gel electrophoresis. J Proteome Res 2009, 8:4835-4843.

80. Wung BS, Cheng JJ, Chao YJ, Hsieh HJ, Wang DL: Modulation of Ras/Raf/ extracellular signal-regulated kinase pathway by reactive oxygen species is involved in cyclic strain-induced early growth response- 1 gene expression in endothelial cells. Circ Res 1999, 84:804-812. 
81. Fourquet $\mathrm{S}$, Guerois R, Biard D, Toledano MB: Activation of NRF2 by nitrosative agents and $\mathrm{H} 2 \mathrm{O} 2$ involves KEAP1 disulfide formation. J Biol Chem 2010, 285:8463-8471

82. Brigelius-Flohe R, Flohe L: Basic principles and emerging concepts in the redox control of transcription factors. Antioxid Redox Signal 2011, 15:2335-2381.

83. Wung BS, Cheng JJ, Hsieh HJ, Shyy YJ, Wang DL: Cyclic strain-induced monocyte chemotactic protein-1 gene expression in endothelial cells involves reactive oxygen species activation of activator protein 1. Circ Res 1997, 81:1-7.

84. Chappell DC, Varner SE, Nerem RM, Medford RM, Alexander RW: Oscillatory shear stress stimulates adhesion molecule expression in cultured human endothelium. Circ Res 1998, 82:532-539.

85. Chiu JJ, Lee PL, Chen CN, Lee Cl, Chang SF, Chen LJ, Lien SC, Ko YC, Usami S, Chien S: Shear stress increases ICAM-1 and decreases VCAM-1 and Eselectin expressions induced by tumor necrosis factor-alpha in endothelial cells. Arterioscler Thromb Vasc Biol 2004, 24:73-79.

86. Chiu JJ, Chen $\amalg$, Lee PL, Lee Cl, Lo LW, Usami S, Chien S: Shear stress inhibits adhesion molecule expression in vascular endothelial cells induced by coculture with smooth muscle cells. Blood 2003, 101:2667-2674.

87. Haddad O, Chotard-Ghodsnia R, Verdier C, Duperray A: Tumor cell/endothelial cell tight contact upregulates endothelial adhesion molecule expression mediated by NF kappa B: Differential role of the shear stress. Exp Cell Res 2010, 316:615-626.

88. Sucosky P, Balachandran K, Elhammali A, Jo H, Yoganathan AP: Altered shear stress stimulates upregulation of endothelial VCAM-1 and ICAM-1 in a BMP-4- and TGF-beta1-dependent pathway. Arterioscler Thromb Vasc Biol 2009, 29:254-260.

89. Khan BV, Harrison DG, Olbrych MT, Alexander RW, Medford RM: Nitric oxide regulates vascular cell adhesion molecule 1 gene expression and redoxsensitive transcriptional events in human vascular endothelial cells. Proc Natl Acad Sci USA 1996, 93:9114-9119.

90. Thom SR, Bhopale VM, Milovanova TN, Yang M, Bogush M: Thioredoxin reductase linked to cytoskeleton by focal adhesion kinase reverses actin S-nitrosylation and restores neutrophil beta(2) integrin function. J Biol Chem 2012, 287:30346-30357.

91. Isaac J, Tarapore P, Zhang X, Lam YW, Ho SM: Site-specific S-nitrosylation of integrin alpha6 increases the extent of prostate cancer cell migration by enhancing integrin beta1 association and weakening adherence to laminin-1. Biochemistry 2012, 51:9689-9697.

92. Selemidis S, Dusting GJ, Peshavariya H, Kemp-Harper BK, Drummond GR: Nitric oxide suppresses NADPH oxidase-dependent superoxide production by S-nitrosylation in human endothelial cells. Cardiovasc Res 2007 75:349-358.

93. Liu WR, Nakamura H, Shioji K, Tanito M, Oka S, Ahsan MK, Son A, Ishii Y, Kishimoto C, Yodoi Y: Thioredoxin-1 ameliorates myosin-induced autoimmune myocarditis by suppressing chemokine expressions and leukocyte chemotaxis in mice. Circulation 2004, 110:1276-1283.

94. Haendeler J, Hoffmann J, Tischler V, Berk BC, Zeiher AM, Dimmeler S: Redox regulatory and anti-apoptotic functions of thioredoxin depend on Snitrosylation at cysteine 69. Nat Cell Biol 2002, 4:743-749.

95. Hoffmann J, Dimmeler S, Haendeler J: Shear stress increases the amount of S-nitrosylated molecules in endothelial cells: important role for signal transduction. Febs Lett 2003, 551:153-158

96. Hoffmann J, Haendeler J, Zeiher AM, Dimmeler S: TNF alpha and oxLDL reduce protein S-nitrosylation in endothelial cells. J Biol Chem 2001, 276:41383-41387.

97. Marshall HE, Merchant K, Stamler JS: Nitrosation and oxidation in the regulation of gene expression. Faseb Journal 2000, 14:1889-1900.

98. Xanthoudakis S, Miao G, Wang F, Pan YCE, Curran T: Redox Activation of Fos Jun DNA-Binding Activity Is Mediated by a DNA-Repair Enzyme. Embo J 1992, 11:3323-3335.

99. Kumar S, Sun XT, Wedgwood S, Black SM: Hydrogen peroxide decreases endothelial nitric oxide synthase promoter activity through the inhibition of AP-1 activity. Am J Physiol-Lung C 2008, 295:L370-L377.

100. Lima B, Forrester MT, Hess DT, Stamler JS: S-Nitrosylation in Cardiovascular Signaling. Circ Res 2010, 106:633-646.

101. Jaffrey SR, Erdjument-Bromage H, Ferris CD, Tempst P, Snyder SH: Protein Snitrosylation: a physiological signal for neuronal nitric oxide. Nat Cell Biol 2001, 3:193-197.

102. Koek W, Campos PS, France CP, Cheng K, Rice KC: GHB- and baclofeninduced hypothermia in mice: interactions with the GABA-B receptor positive modulator CGP7930, the GABA-B receptor antagonist CGP35348, and the NOS inhibitor L-NAME. Faseb Journal 2009, 23

103. Hess DT, Matsumoto A, Kim SO, Marshall HE, Stamler JS: Protein Snitrosylation: purview and parameters. Nat Rev Mol Cell Bio 2005, 6:150-166.

104. Iwakiri Y, Satoh A, Chatterjee S, Toomre DK, Chalouni CM, Fulton D, Groszmann RJ, Shah VH, Sessa WC: Nitric oxide synthase generates nitric oxide locally to regulate compartmentalized protein S-nitrosylation and protein trafficking. Proc Natl Acad Sci USA 2006, 103:19777-19782.

105. Pi X, Wu Y, Ferguson JE 3rd, Portbury AL, Patterson C: SDF-1alpha stimulates JNK3 activity via eNOS-dependent nitrosylation of MKP7 to enhance endothelial migration. Proc Natl Acad Sci USA 2009, 106:5675-5680.

106. Lai YC, Pan KT, Chang GF, Hsu CH, Khoo KH, Hung CH, Jiang YJ, Ho FM, Meng TC: Nitrite-mediated S-nitrosylation of caspase-3 prevents hypoxiainduced endothelial barrier dysfunction. Circ Res 2011, 109:1375-1386.

107. Thibeault S, Rautureau Y, Oubaha M, Faubert D, Wilkes BC, Delisle C, Gratton JP: S-Nitrosylation of beta-Catenin by eNOS-Derived NO Promotes VEGFInduced Endothelial Cell Permeability. Mol Cell 2010, 39:468-476.

108. Wadham C, Parker A, Wang LJ, Xia P: High glucose attenuates protein Snitrosylation in endothelial cells - Role of oxidative stress. Diabetes 2007 56:2715-2721.

109. Santhanam L, Lim HK, Lim HK, Miriel V, Brown T, Patel M, Balanson S, Ryoo $\mathrm{S}$, Anderson $\mathrm{M}$, Irani $\mathrm{K}$, et al: Inducible NO synthase-dependent $\mathrm{S}$ nitrosylation and activation of arginase 1 contribute to age-related endothelial dysfunction. Circ Res 2007, 101:692-702.

110. Matsushita K, Morrell CN, Cambien B, Yang SX, Yamakuchi M, Bao C, Hara MR, Quick RA, Cao W, O'Rourke B, et al: Nitric oxide regulates exocytosis by S-nitrosylation of N-ethylmaleimide-sensitive factor. Cell 2003, 115:139-150.

111. Kang-Decker N, Cao S, Chatterjee S, Yao J, Egan LJ, Semela D, Mukhopadhyay D, Shah V: Nitric oxide promotes endothelial cell survival signaling through S-nitrosylation and activation of dynamin-2. J Cell Sci 2007, 120:492-501.

112. Chen YJ, Ku WC, Lin PY, Chou HC, Khoo KH: S-alkylating labeling strategy for site-specific identification of the s-nitrosoproteome. J Proteome Res 2010, 9:6417-6439.

113. Erwin PA, Mitchell DA, Sartoretto J, Marletta MA, Michel T: Subcellular targeting and differential S-nitrosylation of endothelial nitric-oxide synthase. J Biol Chem 2006, 281:151-157.

114. Ravi K, Brennan LA, Levic S, Ross PA, Black SM: S-nitrosylation of endothelial nitric oxide synthase is associated with monomerization and decreased enzyme activity. Proc Natl Acad Sci USA 2004, 101:2619-2624.

115. Erwin PA, Lin AJ, Golan DE, Michel T: Receptor-regulated dynamic Snitrosylation of endothelial nitric-oxide synthase in vascular endothelial cells. J Biol Chem 2005, 280:19888-19894.

116. Martinez-Ruiz A, Villanueva L, Gonzalez de Orduna C, Lopez-Ferrer D, Higueras MA, Tarin C, Rodriguez-Crespo I, Vazquez J, Lamas S: S-nitrosylation of Hsp90 promotes the inhibition of its ATPase and endothelial nitric oxide synthase regulatory activities. Proc Natl Acad Sci USA 2005, 102:8525-8530.

117. Benhar M, Forrester MT, Stamler JS: Protein denitrosylation: enzymatic mechanisms and cellular functions. Nat Rev Mol Cell Bio 2009, 10:721-732

118. Ni CW, Hsieh HJ, Chao YJ, Wang DL: Interleukin-6-induced JAK2/STAT3 signaling pathway in endothelial cells is suppressed by hemodynamic flow. Am J Physiol-Cell Ph 2004, 287:C771-C780.

119. Tsai YC, Hsieh HJ, Liao F, Ni CW, Chao YJ, Hsieh CY, Wang DL: Laminar flow attenuates interferon-induced inflammatory responses in endothelial cells. Cardiovasc Res 2007, 74:497-505.

120. Murphy E, Kohr M, Sun J, Nguyen T, Steenbergen C: S-nitrosylation: A radical way to protect the heart. J Mol Cell Cardiol 2012, 52:568-577.

doi:10.1186/1423-0127-21-3

Cite this article as: Hsieh et al: Shear-induced endothelial mechanotransduction: the interplay between reactive oxygen species (ROS) and nitric oxide (NO) and the pathophysiological implications. Journal of Biomedical Science 2014 21:3. 